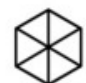 \\ LEUPHANA \\ UNIVERSITÄT LÜNEBURG
}

\section{Variational pragmatics}

Barron, Anne ; Schneider, Klaus Peter

Published in:

Intercultural Pragmatics

DOI:

10.1515/IPRG.2009.023

Publication date:

2009

\section{Document Version}

Publisher's PDF, also known as Version of record

Link to publication

Citation for pulished version (APA):

Barron, A., \& Schneider, K. P. (2009). Variational pragmatics: Studying the impact of social factors on language use in interaction. Intercultural Pragmatics, 6(4), 425-442. https://doi.org/10.1515/IPRG.2009.023

\section{General rights}

Copyright and moral rights for the publications made accessible in the public portal are retained by the authors and/or other copyright owners and it is a condition of accessing publications that users recognise and abide by the legal requirements associated with these rights.

- Users may download and print one copy of any publication from the public portal for the purpose of private study or research.

- You may not further distribute the material or use it for any profit-making activity or commercial gain

- You may freely distribute the URL identifying the publication in the public portal ?

If you believe that this document breaches copyright please contact us providing details, and we will remove access to the work immediately and investigate your claim. 


\title{
Variational pragmatics: Studying the impact of social factors on language use in interaction
}

\author{
ANNE BARRON and KLAUS P. SCHNEIDER
}

Intercultural pragmatics is usually associated with pragmatic differences between different languages. This seems to be the default reading of the term. However, this reading tacitly ignores that there is no one-to-one relationship between languages and cultures. ${ }^{1}$ Speakers who share the same native language do not necessarily share the same culture. For instance, native speakers of English in Ireland and the United States use language in different ways (e.g., Schneider 1999, 2008). Neither do Americans in the US all use English in the same way (cf., e.g., Barron 2009; Wolfram and Schilling 2006: 93-101). On the other hand, cultures may be shared by speakers with different native languages. Thus, as language use in interaction is shaped by cultural values, pragmatic similarities may occur across languages, while pragmatic differences may occur across varieties of the same language.

Variational pragmatics is a subdiscipline of intercultural pragmatics. Other subdisciplines include contrastive pragmatics, cross-cultural pragmatics, ethnopragmatics, interlanguage pragmatics, and postcolonial pragmatics. Contrastive pragmatics is concerned with inter-lingual differences, i.e., with pragmatic variation between different languages. Crosscultural pragmatics, on the other hand, compares the ways in which different languages are used in communication. It also deals with native speaker-non-native speaker interaction and with lingua franca communication (cf. Blum-Kulka et al. 1989; House-Edmondson 1986: 282). ${ }^{2}$ Ethnopragmatics is concerned with explaining speech practices in terms of a culture-internal perspective (e.g., in terms of values) rather than in terms of presumed pragmatic universals (cf. Goddard 2006). Interlanguage pragmatics focuses on the specific nature of language use conventions in learner language, e.g., in the English as a foreign language spoken by native speakers of German, and also on the acquisition of these conventions by learners (cf. Kasper 1998; Kasper and Rose 1999; Barron 2003: 26-28). The use of second (as opposed to foreign) languages in interaction is studied in postcolonial pragmatics. In other words, this 
branch examines the use of the language of the colonizers in postcolonial societies, predominantly in public discourse and interethnic communication. English in India and English in Nigeria would be cases in point (cf. Janney 2009; cf. also Sridhar 1996). Finally, variational pragmatics investigates intra-lingual differences, i.e., pragmatic variation between and across L1 varieties of the same language. It is an area of research which has been much neglected to date.

Variational pragmatics can be conceptualized as the intersection of pragmatics with sociolinguistics, or, more specifically, with dialectology as the study of language variation. It is assumed that the social factors analyzed in sociolinguistics have a systematic impact not only on pronunciation, vocabulary and grammar, but also on language use in interaction. Our framework includes two components, one in which social factors are specified, and one in which levels of pragmatic analysis are distinguished. This framework is presented in section 1 of this introductory chapter. In section 2, the following six papers in this special issue are briefly characterized and explicitly related to this framework.

\section{The framework}

\subsection{Social factors}

In our framework (cf. Schneider and Barron 2008a), we distinguish five social factors. These are region, social class, ethnicity, gender, and age (less stable - and less studied - factors such as education and religion may be considered in addition). The impact of region on language was first studied in traditional dialectology, particularly in dialect geography. This study of regional differences was abandoned in the 1960s with the advent of sociolinguistics. Sociolinguists were not initially interested in regional, but only in social differences, particularly differences between speakers in cities (hence 'urban dialectology'). First and foremost, they were interested in the impact of social class and also of ethnicity, later and increasingly in the impact of gender, and finally also of age. Today, modern dialectology, especially in the United States, aims at integrating these two areas, i.e., the study of regional and the study of social factors.

While regional variation is usually mentioned alongside, or in contrast to, social variation, we wish to argue that regional variation is, in fact, a particular type of social variation. As is well known from the discussion of the gender concept, linguists and social scientists are not primarily interested in sexual differences and biological facts, but rather in much more complex social constructs of gender identities, of which there are 
more than just two, and the social construction of such identities, e.g., through language use in interaction. Similarly, we are not interested in race and such superficial properties as color of skin, hair, or eyes, but in ethnic identities which are based on choices, notably behavioral choices including linguistic choices. An obvious example is that in hip-hop culture white male adolescents may adopt a black identity (cf. Cutler 1999). Regarding region, we can, by analogy, say that we are not interested in geographical facts, but in regional affiliations and identities as they manifest themselves in language use (cf. also 1.3 below on methodological implications).

Accordingly, these five factors are all social factors. It is assumed that each of these factors has an impact on language, resulting in varietyspecific preferences and features which can be employed to construe and project speaker identities. More specifically, the five factors identified here can be referred to as macro-social (or macro-sociolinguistic) factors. By contrast, micro-social (or micro-sociolinguistic) factors include power, distance, and other situational factors. The crucial difference between these two types of factors is that macro-social factors concern individual speakers, whereas micro-social factors concern speaker constellations.

The primary aim of variational pragmatics consists in determining the influence of each of the five macro-social factors on language use in interaction. A second aim is to examine the interplay of these factors, e.g., the interplay of gender and age. Other aims include an analysis of the interaction between macro-social and micro-social factors. Further factors to be taken into account are, among others, discourse type and genre (cf. Schneider 2007), register and community of practice, also speech and writing and levels of formality; in short such factors which concern intraindividual variation (for more details and an extended discussion of the macro-social factors examined in the present framework cf. Schneider and Barron 2008a: 16-19).

As mentioned before, these macro-social factors impact not only on pronunciation (phonetics and phonology), vocabulary (onomasiology and semasiology) and grammar (morphology and syntactic features) those linguistic features normally studied in variational linguistics - but also on pragmatic features of language use in interaction.

\subsection{Levels of pragmatic analysis}

It is assumed that the macro-social factors region, social class, ethnicity, gender and age have a systematic influence on language use in interaction and cause pragmatic variation. As long as this area is neglected, our understanding of language, language variation, and language varieties is 
incomplete. Indeed, Leech (1983) sees pragmatics and grammar as complementary domains in the study of language. He maintains that the nature of language can only be understood if both of these domains are considered and also the interaction between them. In this context, Leech uses the term 'grammar' in a broad sense as a synonym for the language system involving not only syntax, but also phonology and semantics (further levels of the language system, such as morphology or lexicology, are not mentioned). In the complementary domain, i.e., in the domain of pragmatics (pragmatics being a synonym for language use), no equivalent levels of analysis are specified.

In the present framework, by contrast, five levels of pragmatic analysis are distinguished. These are termed the formal level, the actional level, the interactional level, the topic level, and the organizational level. The analysis on the formal level takes linguistic forms as its starting point, for instance, discourse markers such as well. The aim is to establish the communicative functions of such markers in interaction (form-tofunction mapping). On the actional level, the analysis starts with an illocution, e.g., request or apology, and here the aim is to establish the formal realizations available to perform the respective speech act (function-toform mapping). On the interactional level, the analysis goes beyond individual acts and focuses on dialogical units; for instance, adjacency pairs, speech act sequences, and the structure of complete speech events. The topic level is the level on which propositions and sequences of propositions and also topic selection and topic development are dealt with. Finally, the organizational level involves the turn taking mechanisms of dialogical discourse and also such phenomena as simultaneous speech and silence (for more details and an extended discussion cf. Schneider and Barron 2008a: 19-21).

\subsection{Some theoretical and methodological issues}

The discussion has shown that variational pragmatics does not dictate any particular theory or methodology. The levels of pragmatic analysis detailed in section 1.2 display the influence of several different traditions in pragmatics. Investigations on the formal level are characteristic of present-day approaches in corpus linguistics and systemic-functional discourse analysis. Analyses on the actional level are, as a rule, rooted in speech act theory and conducted in empirical speech act analysis. Politeness theory is also relevant to this level of analysis in particular, albeit not exclusively. The interactional level, on the other hand, is the focus of sociolinguistic discourse analysis, while the topic level is studied especially in psycholinguistic discourse analysis, as well as in text linguistics and 
genre analysis. Finally, phenomena on the organizational level are those typically examined in ethnomethodology, and more particularly in conversation analysis. ${ }^{3}$

As the component of our framework which details the different levels of pragmatic analysis reflects so many different traditions, the present overall approach could be said to be eclectic. However, we prefer to call it integrative, as we firmly believe that none of the existing approaches provides a full picture of the complexities of language use in interaction, and that therefore the best results are achieved by combining many different approaches. Of course, individual studies may well single out a certain phenomenon on a particular level of the framework and analyze it by adopting a specific approach considered most suitable for the purpose as the study of complex entities necessitates analytic separations and a certain amount of controlled reductionism (cf. also Kasper 1995).

Thus, generally speaking, it is not essential which particular theory or methodology is adopted. What is, however, really crucial for variational pragmatics is that varieties of a language are contrasted. Strictly speaking, it is not possible to establish any variety-exclusive and varietypreferential features of any (regional, socioeconomic, ethnic, etc.) dialect, if this dialect is not explicitly compared to a dialect of the same kind of this same language. For instance, specific features of youth language cannot be determined by analyzing only youth language without contrasting the sample under study with samples from other age groups. The same applies to all other macro-social factors. Ethnomethodologists have acknowledged this fact in relation to national varieties of English. Harvey Sacks and his collaborators, for instance, worked exclusively with American English data in their analyses. Even though they were not actually interested in the varieties of English and pragmatic variation, they note that the features of conversations which they identified in American English were not necessarily specific to American English conversations, but rather may possibly also be found in other national varieties of English to a significantly greater or lesser extent. They note: "that all conversations are in 'American English' is no warrant for so characterizing them. (...) That the materials are all 'American English' does not entail that they are RELEVANTLY 'American English"' (Schegloff and Sacks 1973: 291; original emphasis). Thus, in general terms, a methodological principle can be formulated which can be termed the 'contrastivity principle'.

\section{CONTRASTIVITY PRINCIPLE}

Linguistic features can be considered variety-specific only if the variety under study is contrasted with at least one other variety of the same kind and of the same language. 
Following this principle, features of, e.g., working class language or the language of African Americans can only be established by comparison to, e.g., middle class language or the language of European Americans respectively. In this connection, it must be emphasized that middle class language and the language of European Americans are not superior varieties, despite the fact that they may carry more overt prestige in many contexts.

While this principle is relevant to variational linguistics in general, it is central to variational pragmatics. Studies in variational linguistics focusing on features of pronunciation, lexis or grammar (implicitly) refer to an abstract standard, for which codified rules (explicitly) exist. Studies in variational pragmatics, on the other hand, aim at establishing the language use conventions (in terms of, e.g., appropriateness and politeness) of social groups, for which often no (abstract / explicit) standard exists. Hence, it is crucial to contrast two or more varieties to be able to identify similarities and differences.

Another important methodological principle is that variational pragmatics is empirical. In other words, studies in variational pragmatics are not based on impressionistic and episodical evidence or so-called introspective (i.e., intuitive and fabricated) data, but on collections of material observed or elicited. In an extensive methodological paper, Jucker (2009) reminds us that the use of intuitive data, which he refers to as an 'armchair method' (following Clark and Bangerter 2004), has its merits too, and that the history of pragmatics has seen cases in which influential theories were developed on this basis alone. This certainly applies to Austin's and Searle's speech act theory. It also applies, of course, to Chomsky's work in linguistics outside pragmatics. However, theories such as Searle's or Chomsky's focus on language as such (or 'langage', to use Saussure's term) or languages (essentially in the sense of 'langue') conceptualized as homogeneous entities in which variation is abstracted away. Variational pragmatics on the other hand, like variational linguistics in general, conceives language as "orderly heterogeneity" (Weinreich et al. 1968) and is interested in linguistic performance (or, maybe more precisely, 'parole'). Researchers in this area therefore must work empirically.

Regarding the question of which types of data can or should be used in the analysis, variational pragmatics, unlike approaches permitting no other type than naturally occurring conversation, acknowledges that each and every data type and data collection method has its advantages as well as its shortcomings, and this includes naturally occurring discourse. It further acknowledges that the choice of method depends entirely on the aims and research questions of a project, and that a method 
suitable for one purpose may not be suitable for other purposes (cf. Bardovi-Harlig 1999; Kasper 2000; also Jucker 2009).

Hence, variational pragmatics can be done with a wide range of data types and methods. These include, as the contributions to this special issue illustrate (cf. section 2 below), the use of large electronic corpora (such as the British National Corpus), elicited conversation, role plays and sociolinguistic interviews. Elsewhere, production questionnaires have been used (cf., e.g., Muhr 2008; Schölmberger 2008; Warga 2008), but also naturally occurring everyday conversation (cf., e.g., Placencia 2008).

As the primary aim of variational pragmatics is to study and establish the influence of macro-social factors on language use, and also the interplay of these factors, the best strategy, at least in the initial stages, seems to be to opt for a method which allows a high degree of variable control. Experimental methods, such as questionnaires, interviews and role play, are well suited for this purpose, since the social variables involved can be systematically manipulated (cf. Kasper 2000). Elicited conversation in particular warrants near-natural data, while variables can be controlled fairly easily, and thus contrasts with naturally occurring conversation with all its accidentialities (for examples of covert experiments with high ecological validity, cf. Turnbull 2001; Zimmermann 2004). In general, we can say that the higher the possibility of controlling the relevant variables, the higher the comparability of data from different varieties of the same language and therefore the greater the opportunity of identifying pragmatic differences between these varieties. For this reason, comparability is another crucial methodological issue in variational pragmatics.

A further methodological problem is posed by the macro-social factors themselves. While we generally assume that region, gender, ethnicity, etc. are social factors underlying the construction of identities, it is rather a challenging task to actually investigate them as such. Gender, for instance, is not just a matter of terminology. To simply substitute the term 'gender' for 'sex' in linguistic studies is largely misleading (cf. Cheshire 2002: 423). The influence of such complex social concepts as gender on pragmatic variation can only be investigated properly by studying "the everyday language use of individual women and men in the local communities where the social construction of gender and other identities takes place" (Cheshire 2002: 425). In other words, what is actually required for this purpose are meticulous ethnographic case studies, which can be very time consuming and do not necessarily provide comparable data. Therefore, to enhance comparability, it is recommended to actually focus on sex rather than gender, because sex is much more easily identifiable. As Cheshire notes (2002) "speaker sex is intended to be a purposely broad, unrefined social variable that can be easily taken into account at the 
data-collection stage of research. If all researchers categorize speakers in the same, albeit simplistic way, we can ensure replicability and can draw useful comparisons between studies carried out in a range of communities" (424-425).

At least in the initial stages of variational pragmatics, this type of reductionism seems useful, if not inevitable. Needless to say, it applies not only to gender but, in fact, to all macro-social factors considered in this framework.

Studying all macro-social factors individually helps to determine the impact of each of these factors on language use in interaction. Since, however, every speaker's identity depends on more than one macro-social factor-every speaker belongs to a particular age group, social class, etc. - the interplay of these factors has to be taken into account as well. For instance, the question "to what extent does age interact with other social variables such as class, gender, and ethnicity?" (Eckert 1997: 152) addresses a matter of central concern to variational pragmatics. It is a question dealt with in some of the contributions to this special issue (cf. section 2.1).

\subsection{Development}

The idea to study pragmatic variation across varieties of English was first conceived in the mid-1990s. Schneider (1999), a comparison of compliment responses in American English and Irish English, is an early study in this field. This paper reports on a replication of a study by Chen (1993), who contrasts compliment responses in American English and Chinese. The differences found between the two national varieties of English were explained with reference to Leech's politeness theory (1983).

In 2001, in a conference paper entitled "Pragmatics meets dialectology: Investigating regional variation in language use" (Schneider 2001), a plea was made for the inclusion of pragmatic variation at the sub-national level usually examined in dialectology. This paper was inspired on the one hand by Wolfram and Schilling-Estes, who in their 1998 textbook on "American English: Dialects and Variation," devote a brief section to "Language Use and Pragmatics" (82-90). Here, they mention a wide range of pragmatic phenomena, including e.g. speech act realizations, address forms, conversational openings and closings, topics of conversation and backchanelling, but the observations reported are mainly based on their own communicative experience. A further impulse was an article published about twenty years earlier, in 1978, by Schlieben-Lange and Weydt. This article, entitled "Für eine Pragmatisierung der Dialektologie" ('for a pragmaticization of dialectology'), made a plea to extend the scope 
of dialect studies within German dialectology. It was, however, substantiated only by reports of personal experience and episodic observation.

A parallel development at the time was a proposal by Placencia (1994) that pragmatic variation across intralingual regional varieties merited attention (cf. also Placencia 2008). This proposal focused above all on regional varieties of Spanish. Indeed, to date there exists more research on the pragmatics of national varieties of Spanish than of varieties of any other language (cf., e.g., García 2008 for an overview). It is fitting, therefore, that the papers by Félix-Brasdefer and García in the present special issue focus on regional varieties of Spanish.

2005 saw the first publication to appear with the term 'variational pragmatics" in its title: "Variational pragmatics in the foreign language classroom" (Barron 2005a). This paper highlighted the research desideratum in the study of macro-social pragmatic variation across intralingual varieties and by means of data from regional intra-lingual pragmatic studies, attempted to highlight a number of parameters relevant to speech act studies of intra-lingual pragmatic variation. On this basis, a case was made for language teaching to include a variational perspective on conventions of language use. 2005 also saw the publication of "The Pragmatics of Irish English", a collection of papers edited by the editors of this special issue (Barron and Schneider 2005). While all contributions to this collection analyze aspects of the pragmatics of this particular national variety of the English language, some of the papers also compare their findings with findings from other national varieties of English, especially English as it is spoken in the United Kingdom and also in the United States of America (cf. Kallen 2005; Barron 2005b; Schneider 2005).

Variational pragmatics was officially launched in 2005, at the 9th International Pragmatics Conference held in Riva del Garda, Italy. At this conference, the editors of the present special issue organised the panel "Variational pragmatics: Cross-cultural approaches," which they opened with a talk on "Variational pragmatics: Contours of a new discipline". The focus of this panel was on regional variation on the national and subnational level. An edited volume entitled "Variational Pragmatics: A Focus on Regional Varieties in Pluricentric Languages" appeared in 2008 (Schneider and Barron 2008b). Its introductory chapter set out in detail the need for research in variational pragmatics and also the framework proposed for variational pragmatics (Schneider and Barron 2008a).

The present special issue is based on two further panels organized by the present editors on variational pragmatics, namely the panel "Variational pragmatics: A focus on region, age and gender" held at the 10th International Pragmatics Conference in Göteborg in July 2007 and also 
the workshop "Pragmatic variation: the interplay of micro-social and macro-social factors" held at the Sociolinguistics Symposium 17 conference which took place in Amsterdam in April 2008. While the Göteborg panel focused on three particular macro-social factors, namely region, age and gender, and investigated the influence of these factors on intralingual pragmatic variation, the Amsterdam workshop investigated the interplay of individual macro-social factors on pragmatic variation, and also the interplay of macro-social and micro-social factors. The papers by García and by O'Keeffe and Amador Moreno in the present special issue are based on contributions to the IPrA panel in Göteborg (cf. section 2 for further details). Three additional papers, those by Farr and Murphy, Macaulay, and also Pichler, are based on contributions to the Sociolinguistics Symposium 17 in Amsterdam. The paper by César FélixBrasdefer was invited at a later stage.

\section{The papers}

This special issue on variational pragmatics (VP) provides an opportunity to illustrate the types of questions and issues addressed in the area of variational pragmatics. The following overview of the special issue papers is, thus, structured as section 1 above. It focuses first on the macro-social and micro-social factors addressed (2.1), the levels of pragmatic analysis investigated (2.2) and following this on the methodologies employed (2.3). The paper concludes with a more detailed overview of the individual papers (2.4).

\subsection{Addressing social factors}

As highlighted by the titles of the IPrA and SS17 panels detailed in 1.4, and also in Schneider and Barron (2008a) and in 1.1 above, the influence of macro-social factors and micro-social factors, and indeed also the interplay of these factors is an important focus of analysis in variational pragmatics. The macro-social factor region, particularly at the national level, is the focus of much of the variational pragmatic research which exists to date (cf. Schneider and Barron 2008b), and indeed in the present special issue, region also has a particular status. Six intralingual varieties of Spanish are dealt with, namely, Costa Rican Spanish, Dominican Spanish, Mexican Spanish (Félix-Brasdefer), Argentinean Spanish, Peruvian Spanish, and Venezuelan Spanish (García). In addition, regional varieties of English are investigated. Irish English is compared to Standard English (O'Keeffe and Amador Moreno), and to a limited extent to Brit- 
ish English and American English (Farr and Murphy). Both Macaulay and Pichler deal with specific pragmatic features of a particular local variety of English. Pichler investigates Berwick English, while Macaulay focuses on Glaswegian English. Apart from region, the macro-social variables of age and gender and their effect on intralingual pragmatic conventions are also addressed in the present special issue. All papers addressing these macro-social factors deal with both age and gender together. Pichler, for instance, investigates how age and gender influence the formal realizations of the discourse markers $I$ DON'T KNOW and $I$ DON'T THINK. Also, Macauley looks at how age and gender influence speakers' pragmalinguistic preferences for particular forms of intensifiers and quotatives. Finally, Farr and Murphy investigate how age and gender influence speakers' use of religious references in non-religious contexts in Irish English. As seen in these examples, the interaction between macro-social factors is a common focus of analysis in the special issue. In addition, a number of papers also address the interaction of macro-social with micro-social factors. César Félix-Brasdefer, for instance, focuses on region and also on the interplay of situation as a micro-social factor with region. He analyses three symmetric situations with different levels of social distance across the varieties of Costa Rican, Dominican and Mexican Spanish. The paper by Fiona Farr and Bróna Murphy is a further example. As well as investigating the interplay of gender, age and region on the use and choice of religious references, these authors also highlight situational influences. They point out that the use of religious references in non-religious contexts is influenced by genre, such references occurring primarily in spoken language of an informal nature.

\subsection{Addressing different levels of pragmatic analysis}

As detailed above (cf. section 1.2), five levels of pragmatic analysis are distinguished in the framework of variational pragmatics, namely the formal, the actional, the interactional, the topic and the organizational levels (cf. Schneider and Barron 2008a: 19-21). The papers in this special issue represent analyses on the formal, actional, and interactional levels. There is, however, a clear emphasis on the formal level, with papers by Fiona Farr and Bróna Murphy, Anne O'Keeffe and Carolina Amador Moreno, Heike Pichler and also Ronald Macaulay all focusing on the communicative functions which particular forms or structures may have in discourse. Farr and Murphy, for instance, find religious references to signal emotion, O'Keeffe and Amador Moreno suggest that the construction 'be after + Verb-ing' serves a number of pragmatically specialized functions, such as an immediacy/recency function, a narrative function, 
a news marking function and a scolding function. Pichler finds nonlocalized discourse variants to display a function-specific patterning, but localized variants not to carry any functional load, but social meaning. Finally, Macaulay discusses a number of innovative forms of adolescent speech, some of which function as quotatives, others which have a mitigating function. César Félix-Brasdefer and Carmen García, on the other hand, focus on both the actional and interactional levels of analysis. Félix-Brasdefer investigates requests across intralingual regional varieties. He deals in particular with initial and post-initial requests. Indeed, his focus on speech act sequences is a particularly innovative development in speech act analyses, research to date having concentrated overridingly on the single turn. García analyses the strategies employed at various stages in employer-employee reprimands.

\subsection{Addressing methodology}

Schneider and Barron (2008a: 2-7) highlight that the origins of variational pragmatics lie in the failure of sociolinguistics to address the pragmatic level of language to any systematic extent and in the failure of pragmatics to address variation due to macro-social variables, such as region, socio-economic status, ethnic identity, gender and age. It is, thus, fitting that the methodologies employed in this special issue are both broadly pragmatic and traditionally sociolinguistic. Ronald Macaulay, for instance, employs quantitative sociolinguistic methods. So too does Heike Pichler. However, in her analysis, Pichler combines a quantitative Labovian approach with qualitative methods from conversation analysis. On the other hand, Félix-Brasdefer and also García both employ speech act theory, García working additionally within Spencer-Oatey's (2005) framework of rapport management. Finally, both Farr and Murphy and also O'Keeffe and Amador Moreno adopt corpus linguistic methods in their investigations. On the related issue of data, we note that all six papers in this special issue are the product of empirical research. Those by Farr and Murphy and also by O'Keeffe and Amador Moreno use naturally-occurring data, the remaining four experimental data. The natural data are obtained primarily from the Limerick Corpus of Irish English (LCIE), although a range of other corpora are also employed by Farr and Murphy (e.g. British National Corpus (BNC), Corpus of Professional American English (CSPAE), Michigan Corpus of Academic Spoken English (MICASE) and The Bergen Corpus of London Teenage Language (COLT)). The experimental data were collected using roleplays (Félix-Brasdefer, García), semi-structured sociolinguistic interviews (Pichler) and elicited conversation (Macaulay). 


\subsection{The individual papers}

Turning to the individual papers, Carmen García examines intralingual regional pragmatic variation. Specifically, she deals with the influence of national culture on reprimands in Argentinean, Peruvian and Venezuelan Spanish using role-play data. Micro-social factors are kept stable, the analysis focusing on reprimands in one particular situation across cultures. In this situation, a superordinate reprimands an employee for coming late to work, leaving early and not doing his/her work. Adopting Spencer-Oatey's rapport management framework (2005), García examines how social relationships are constructed, maintained or threatened in this reprimand situation. Her findings show that all three cultural groups favored transactional over interactional wants. However, differences were also apparent, with Peruvians and Venezuelans exhibiting a rapport-challenging orientation, coercing the interlocutor and emphasizing the power differential existing between boss and employee. Native speakers of Argentinean Spanish, in contrast, preferred a rapport maintenance orientation. In other words, they showed respect to their interlocutor, expressed empathy and also a desire for involvement. In addition, there were also differences in efforts made by employers to protect their identity face. While Peruvian speakers showed no interest in protecting their identity face, Venezuelan speakers, similar to Argentinean speakers, were concerned with protecting face.

Also focusing on national varieties of the pluricentric language Spanish, César Félix-Brasdefer's contribution addresses the requesting conventions employed in three role play situations across Costa Rican, Dominican, and Mexican Spanish. In other words, the paper investigates the influence of the macro-social factor region taken on a national level on pragmatic conventions and also the interplay of region with the microsocial factor, situation. The analysis concentrates on the request strategies (both initial and post-initial requests) employed as well as on internal mitigation employed. Particularly innovative in this paper is the focus on requests in sequence and also the analysis of prosodic downgraders in addition to the usual focus on syntactic and lexical and phrasal downgraders. Findings show a general preference for conventional indirectness in the initial request and a preference for impositives in post-initial requests across all three regional varieties. However, it was also found that the realization of requests is conditioned by cultural group and also situation. The Costa Ricans and Mexicans were found, for instance, to prefer less direct forms and more lexical and syntactic downgraders than the speakers of Dominican Spanish. That is, the Costa Ricans and Mexicans expressed their requests more tentatively and deferentially 
relative to the Dominicans. Félix-Brasdefer, comparing his findings with those of previous studies, suggests parallels between the varieties of Spanish investigated and other varieties at both the national and subnational levels.

Anne O'Keeffe and Carolina Amador Moreno discuss the 'be after + Verb-ing' structure from a pragmatic perspective. In this paper, they build on previous research which has established this form as a structure unique to Irish English. In their corpus analysis of the LCIE, O'Keeffe and Amador Moreno identify four functions fulfilled by the 'be after + Verb-ing' structure. These include communication of immediacy in terms of outcome rather than time-frame, function as a metalinguistic trigger in narratives signposting the main event of the storyline, a news marking function and finally a function in the context of scolding and often mock scolding/self-deprecation. These authors also show the structure to be widely used by both genders and also among younger speakers of Irish English today. They predict that it will remain an exclusive feature of this national variety.

Fiona Farr and Bróna Murphy also use the LCIE as their primary data base to study religious references in non-religious contexts in Irish English. Their research deals with the macro-social factors gender and age, and also with the role played by genre in the study of language in use. They establish that religious references used to signal emotions are primarily found in spoken language of an informal nature. In addition, the analysis shows that the use, and also the preferred pragmalinguistic means to signal emotions using religious references, differ by gender and age. Religious references were found, for instance, to be employed to a particularly high extent by male speakers to signal emotions. On the formal level, God was used in the female data most often, particularly by the speakers in their 70s/80s. Stronger forms, such as Jesus, by contrast were employed extensively by younger speakers. The use of Christ is a final example, this form being found to be a feature of male talk.

Heike Pichler's paper investigates the use of localized and non-localized full and reduced variants of the discourse markers $I$ DON'T KNOW and $I$ DON'T THINK among working class speakers from Berwick-upon-Tweed, a town in the far north-east of England, five kilometers south of the Scottish-English border. The analysis reveals that non-localized variants of both of these variables display a function-specific patterning. Localized variants, on the other hand, do not carry a functional load, fulfilling a range of interpersonal and textual functions. They were, however, found to be sensitive to social factors, and on this level serve to index speakers' local and/or regional identities. Pichler concludes with a call for further research into the form and function of discourse variables and also for a 
better integration of qualitative methods in the study of language variation and change in discourse.

The final paper in the special issue is a paper by Ronald Macaulay which focuses predominantly on intensifiers and quotatives used in the speech of working class adolescents in Glasgow. Macaulay identifies a number of innovative forms of intensifiers (e.g., pure, so, healthy, heavy, mad) and quotatives (e.g., be like that, go like that, be like, done [that]) to have developed locally in the speech of these adolescents. In addition, age and gender differences within the corpus of adolescent speech are established. While some of these differences (e.g., higher use of subordinate clauses among older females) appear to be due to development issues, other differences are sociolinguistic in nature. Similar to Pichler, Macaulay makes a call for more sociolinguists to include discourse features in analyses of linguistic variation.

This special issue has been designed to continue and strengthen the growing trend towards research on pragmatic variation by focusing on the effect of macro-social and micro-social factors on a variety of levels of analysis using a range of data. It is hoped that it will provide readers with novel and interesting perspectives on variational pragmatics, the study of intra-lingual pragmatic variation relative to such macro-social factors as region, social class, ethnicity, gender, and age.

\section{Acknowledgements}

The editors wish to express their gratitude to all those involved with the formal side of this special issue and, in particular, to Ilka Flöck for her role in formatting the manuscript. Thanks also to the anonymous reviewers, and of course to the authors themselves for their cooperation in the project.

\section{Notes}

1. Interestingly, in the programmatic goals set out for this very journal, Intercultural Pragmatics, there is explicit mention of the intention to focus on "theoretical and applied pragmatics research that involves more than one language and culture or varieties of one language" (cf. http://www.degruyter.com/journals/intcultpragm/detailEn.cfm). In a previous issue, Clyne (2006), focusing on regional pragmatic variation, takes up this matter, but as he also shows, research on intralingual pragmatic variation remains a programmatic goal not only in this journal, but in the research in general (cf. Schneider and Barron 2008a: 2-7). 
2. We are aware of different understandings of these terms. In the present context, however, such definitions suffice.

3. Needless to say, conversation analysts adopt a different perspective to their data, not seeing social relations, social identities, or setting as relevant to an analysis unless their significance is seen or understood in the text.

\section{References}

Bardovi-Harlig, Kathleen (1999). Researching method. In Pragmatics and Language Learning (Monograph Series 9), Lawrence F. Bouton (ed.), 237-264. Urbana, IL: University of Illinois at Urbana-Champaign, Division of English as an International Language.

Barron, Anne (2003). Acquisition in interlanguage pragmatics: Learning how to do things with words in a study abroad context (Pragmatics and Beyond New Series 108). Amsterdam and Philadelphia: Benjamins.

Barron, Anne (2005a). Variational pragmatics in the foreign language classroom. System 33(3): 519-536.

Barron, Anne (2005b). Offering in Ireland and England. In The Pragmatics of Irish English (Trends in Linguistics. Studies and Monographs 164), Anne Barron and Klaus P. Schneider (eds.), 141-176. Berlin and New York.

Barron, Anne (2009). Apologies across the U.S.A. In Language in Life, and a Life in Language. Jacob Mey-A Festschrift, Ken Turner and Bruce Fraser (eds.), 9-17. Chennai: Emerald.

Barron, Anne and Klaus P. Schneider (eds.) (2005). The Pragmatics of Irish English. (Trends in Linguistics. Studies and Monographs 164). Berlin and New York: Mouton de Gruyter.

Blum-Kulka, Shoshana, Juliane House and Gabriele Kasper (1989). Investigating crosscultural pragmatics: An introductory overview. In Cross-cultural pragmatics: Requests and apologies (Advances in Discourse Processes 31), Shoshana Blum-Kulka, Juliane House and Gabriele Kasper (eds.), 1-34. Norwood, NJ: Ablex.

Chen, Rong (1993). Responding to compliments: A contrastive study of politeness strategies between American English and Chinese speakers. Journal of Pragmatics 20(1): 49-75.

Cheshire, Jenny (2002). Sex and gender in variationist research. In Handbook of language variation and change (Blackwell Handbook in Linguistics), John K. Chambers, Peter Trudgill, and Natalie Schilling-Estes (eds.), 423-443. Oxford: Blackwell.

Clark, Herbert H. and Adrian Bangerter (2004). Changing ideas about reference. In Experimental Pragmatics (Palgrave Studies in Pragmatics, Language and Cognition), Ira A. Noveck and Dan Sperber (eds.), 25-49. Basingstoke: Palgrave Macmillan.

Clyne, Michael (2006). Some thoughts on pragmatics, sociolinguistic variation, and intercultural communication. Intercultural Pragmatics 3(1): 95-105.

Cutler, Cecilia (1999). Yorkville Crossing: White teens, hip hop and African American English. Journal of Sociolinguistics 3(4): 428-443.

Eckert, Penelope (1997). Age as a sociolinguistic variable. In The handbook of sociolinguistics (Blackwell Handbooks in Linguistics 4), Florian Coulmas (ed.), 151-167. Oxford: Blackwell.

García, Carmen (2008). Different realizations of solidarity politeness: Comparing Venezuelan and Argentinean invitations. In Variational pragmatics: A focus on regional varieties in pluricentric languages (Pragmatics and Beyond New Series 178), Klaus P. Schneider and Anne Barron (eds.), 269-305. Amsterdam and Philadelphia: Benjamins. 
Goddard, Cliff (2006). Ethnopragmatics. A new paradigm. In Ethnopragmatics: Understanding discourse in cultural context (Applications in Cognitive Linguistics 3), Cliff Goddard (ed.), 1-30. Berlin and New York: Mouton de Gruyter.

House-Edmondson, Juliane (1986). Cross-cultural pragmatics and foreign language teaching. In Probleme und Perspektiven der Sprachlehrforschung, Karl-Richard Bausch, Frank G. Königs and Rainer Kogelheide (eds.), 281-295. Frankfurt a.M.: Scriptor.

Janney, Richard (2009). Toward a postcolonial pragmatics. In Language in Life, and a Life in Language. Jacob Mey-A Festschrift, Ken Turner and Bruce Fraser (eds.), 193-202. Chennai: Emerald.

Jucker, Andreas (2009). Speech act research between armchair, field and laboratory: The case of compliments. Journal of Pragmatics 41(8): 1611-1635.

Kallen, Jeffrey L. (2005). Silence and mitigation in Irish English discourse. In The Pragmatics of Irish English (Trends in Linguistics. Studies and Monographs 164), Anne Barron and Klaus P. Schneider (eds.), 47-71. Berlin and New York: Mouton de Gruyter.

Kasper, Gabriele (1995). Wessen Pragmatik? Für eine Neubestimmung fremdsprachlicher Handlungskompetenz. Zeitschrift für Fremdsprachenforschung 6(1): 69-94.

Kasper, Gabriele (1998). Interlanguage pragmatics. In Learning foreign and second languages: Perspectives in research and scholarship (Teaching Languages, Literatures, and Cultures 1), Heidi Byrnes (ed.), 183-208. New York: Modern Language Association.

Kasper, Gabriele (2000). Data collection in pragmatics research. In Culturally speaking: Managing rapport through talk across cultures (Open Linguistics Series), Helen SpencerOatey (ed.), 316-341. London and New York: Continuum.

Kasper, Gabriele and Kenneth R. Rose (1999). Pragmatics and SLA. Annual Review of Applied Linguistics 19: 81-104.

Leech, Geoffrey (1983). Principles of Pragmatics (Longman Linguistics Library 30). London: Longman.

Muhr, Rudolf (2008). The pragmatics of a pluricentric language: A comparison between Austrian German and German German. In Variational pragmatics: A focus on regional varieties in pluricentric languages (Pragmatics and Beyond New Series 178), Klaus P. Schneider and Anne Barron (eds.), 209-242. Amsterdam and Philadelphia: Benjamins.

Placencia, María Elena (1994). Pragmatics across varieties of Spanish. Donaire 2: 65-77.

Placencia, María Elena (2008). Requests in corner shop transactions in Ecuadorian Andean and Coastal Spanish. In Variational pragmatics: A focus on regional varieties in pluricentric languages (Pragmatics and Beyond New Series 178), Klaus P. Schneider and Anne Barron (eds.), 307-332. Amsterdam and Philadelphia: Benjamins.

Schegloff, Emanuel A. and Harvey Sacks (1973). Opening up closings. Semiotica VIII(4): 290-327.

Schlieben-Lange, Brigitte and Harald Weydt (1978). Für eine Pragmatisierung der Dialektologie. Zeitschrift für Germanistische Linguistik 6(3): 257-282 [pp. 257-260 are given twice in this volume, each time with different content].

Schneider, Klaus P. (1999). Compliment responses across cultures. In On language in theory and practice: In honour of Janusz Arabski on the occasion of his 60th birthday Vol. 1, M. Wysocka (ed.), 162-172. Katowice: Wydawnictwo Uniwersytetu Śląskiego.

Schneider, Klaus P. (2001). Pragmatics meets dialectology: Investigating regional variation in language use. Invited paper presented at the international workshop New Orientations in the Study of Regionalism, University of Bonn, Germany, 16-19 July 2001.

Schneider, Klaus P. (2005). 'No problem, you're welcome, anytime': Responding to thanks in Ireland, England, and the U.S.A. In The pragmatics of Irish English (Trends in Linguistics. Studies and Monographs 164), Anne Barron and Klaus P. Schneider (eds.), 101-139. Berlin and New York: Mouton de Gruyter. 
Schneider, Klaus P. (2007). Genre matters: Textual and contextual constraints on contemporary English speech behaviour. Anglia 125(1): 59-83.

Schneider, Klaus P. (2008). Small talk in England, Ireland, and the USA. In Variational pragmatics: A focus on regional varieties in pluricentric languages (Pragmatics and Beyond New Series 178), Klaus P. Schneider and Anne Barron (eds.), 99-139. Amsterdam and Philadelphia: Benjamins.

Schneider, Klaus P. and Anne Barron (2008a). Where pragmatics and dialectology meet: Introducing variational pragmatics. In Variational pragmatics: A focus on regional varieties in pluricentric languages (Pragmatics and Beyond New Series 178), Klaus P. Schneider and Anne Barron (eds.), 1-32. Amsterdam and Philadelphia: Benjamins.

Schneider, Klaus P. and Anne Barron (eds.) (2008b). Variational pragmatics: A focus on regional varieties in pluricentric languages (Pragmatics and Beyond New Series 178). Amsterdam and Philadelphia: Benjamins.

Schölmberger, Ursula (2008). Apologizing in French French and Canadian French. In Variational pragmatics: A focus on regional varieties in pluricentric languages (Pragmatics and Beyond New Series 178), Klaus P. Schneider and Anne Barron (eds.), 329-350. Amsterdam and Philadelphia: Benjamins.

Spencer-Oatey, Helen (2005). (Im)Politeness, face and perceptions of rapport: Unpackaging their bases and interrelationships. Journal of Politeness Research 1(1): 95-119.

Sridhar, Kamal (1996). The pragmatics of South Asian English. In: South Asian English: Structure, use and uses, Robert J. Baumgardner (ed.), 141-157. Urbana and Chicago: University of Illinois Press.

Turnbull, William (2001). An appraisal of pragmatic elicitation techniques for the social psychological study of talk: The case of request refusals. Pragmatics 11(1): 31-61.

Warga, Muriel (2008). Requesting in German as a pluricentric language. In Variational pragmatics: A focus on regional varieties in pluricentric languages (Pragmatics and Beyond New Series 178), Klaus P. Schneider and Anne Barron (eds.), 243-264. Amsterdam and Philadelphia: Benjamins.

Weinreich, Uriel, William Labov and Marvin I. Herzog (1968). Empirical foundations for a theory of language change. In Directions for historical linguistics: A symposium, W. P. Lehmann and Yakov Malkiel (eds.), 95-195. Austin: University of Texas Press.

Wolfram, Walt and Schilling-Estes, Natalie (1998). American English: Dialects and variation. Malden, MA: Blackwell.

Wolfram, Walt and Schilling-Estes, Natalie (2006). American English: Dialects and variation. 2nd edn. Malden, MA: Blackwell.

Zimmermann, Rüdiger (2004). Interlanguage pragmatics: Methodology, compliment responses, refusals. In Pragmatics and language learning, Janusz Arabski (ed.), 97-111. Kraków: Universitas.

a.barron@uni-bonn.de k.schneider@uni-bonn.de 